Artículo

\title{
Elaboración de infografías: hacia el desarrollo de competencias del siglo XXI
}

\author{
Infographic design: toward the development of the XXI-century \\ competences \\ Cristián Roney Aguirre* \\ cristianagar@unisabana.edu.co
}

Eduardo Menjívar Valencia**

eduardomeva@unisabana.edu.co

Heimi Liliana Morales ${ }^{\star * *}$

heimimocu@unisabana.edu.co

ISSN 1996-1642, Editorial Universidad Don Bosco, año 9, No.15, enero-junio de 2015, pp. 23-37

Recibido: 19 de septiembre de 2014. Aprobado: 16 de diciembre de 2014

\begin{abstract}
Resumen
Este artículo aborda la infografía, su uso en la educación y las competencias que desarrollan los estudiantes al elaborarla. La infografía tiene su origen en el periodismo y por su potencial comunicativo ha tenido impacto en los lectores desde hace varias décadas, convirtiéndose en uno de los recursos más utilizados por los Medios de Comunicación. Con el paso de los años, de manera paulatina, se ha incorporado al campo educativo, generando nuevas dinámicas de transmisión de información. La infografía, al ser una combinación de elementos visuales (imágenes, gráficos, vídeo, audio, texto) y que al ser incorporada de manera adecuada en el aula de clase, puede potenciar en los estudiantes una mejor comprensión y descripción de temas complejos permitiendo al mismo tiempo el desarrollo de competencias que los prepara frente a una sociedad culturalmente visual. El uso de las infografías en el proceso de enseñanza-aprendizaje refleja de manera explícita el desarrollo de las competencias comunicativas, informacional y digital, que son las competencias del siglo XXI.
\end{abstract}

Palabras clave: infografía, educación, comunicación, competencias, enseñanzaaprendizaje

\begin{abstract}
This article approaches infographics, its use in education and the competences developed by students in its design. Infographics originated in journalism and due to its communicative potential it has impacted readers for decades, becoming in one of the most used resources by mass media. Through time, it has been incorporated to the educational field, generating new ways of conveying information. Infographics is a combination of visual elements (images, graphics, video, text) that when appropriately incorporated to the classroom, it can promote the student's better understanding and description of complex topics which in time develops the competences needed in a society that is culturally visual. The use of infographics in the teaching-learning process reflects in an explicit way not only its design but also the development of the communicative, informational and digital abilities, which are the competences needed in the XXI century.
\end{abstract}

Keywords: infographics, education, communication, competences, teachinglearning process

\footnotetext{
* Licenciado en Diseño Tecnológico, Universidad Pedagógica Nacional de Colombia y estudiante de Maestría en Informática Educativa, Universidad de la Sabana, Colombia.

** Licenciado en Ciencias de la Comunicación, Universidad Don Bosco, estudiante de Maestría en Informática Educativa, y profesor de la Universidad de la Sabana, Colombia.

*** Licenciada en Diseño Tecnológico, Universidad Pedagógica Nacional; estudiante de Maestría en Informática Educativa, Universidad de la Sabana.
}

Para citar este artículo: Aguirre, C.; Menjivar, E. y Morales, H. (2014). Elaboración de infografías hacia el desarrollo de las competencias del siglo XXI. Diá-logos 15, 23-37. 


\section{Introducción}

El auge de las nuevas tecnologías y su masificación ha provocado un cambio en la manera de crear, presentar y publicar información. Desde hace varios años, se empezó a trabajar en la consecución de imágenes, gráficos, tablas, mapas y diferentes elementos visuales de calidad, a través de recursos digitales, inicialmente utilizando herramientas básicas como Paint o Corel Draw hasta utilizar herramientas de mayor complejidad como Illustrator, Photoshop, Studio 3D y Maya.

Al mismo tiempo que se produce un avance en el trabajo de la imagen, estas se van incorporando y difundiendo a través de los nuevos medios de comunicación. La red de internet empieza a jugar un papel fundamental, debido a que permite la posibilidad, no solo de ser un observador pasivo, sino de crear y editar todo tipo de contenidos, incluyendo los formatos gráficos.

La Red cobra mayor relevancia al proveer a los usuarios de distintas herramientas en línea, que le facilitan la manera de realizar tareas de creación y edición de cualquier tipo de contenido. Con esto se disminuye el tiempo de trabajo y sobretodo permite que con pocas habilidades tecnológicas cualquier persona pueda generar contenidos educativos, visualmente impactantes sin límites de tiempo, costo o capacidad de memoria.

Algunos de esos contenidos corresponden a infografías, pasando de ser un recurso visual exclusivo de la labor periodística a formar parte de estrategias didácticas de muchos docentes; es así, que se vuelve necesario identificar ¿cuáles competencias desarrollan los estudiantes al crear infografías?

\section{Generalidades de la infografía}

Vale la pena resaltar que la infografía es una combinación de elementos visuales que aporta un despliegue gráfico de la información. De acuerdo con el Manual de Estilo de Clarín (1997, citado por Minervini, 2005) se recurre a la infografía principalmente para presentar información compleja, que se puede sintetizar, brindar detalles y hacer su lectura más llamativa. En este sentido, el término infografía es el resultado del acrónimo info y grafías, tal como lo ilustra la figura 1.

Es una expresión que surge en el periodismo con el objetivo de informar de una manera diferente mediante el empleo de dibujos, imágenes, gráficos, esquemas, estadísticas, mapas, entre otras; pero que se ha extendido a través de todos los medios de comunicación y, en especial, en las redes sociales. Son utilizadas prácticamente en todas las profesiones, especialmente en aquellas en las que se usa un vocabulario técnico, como en las ciencias naturales, en economía, finanzas, medicina, física, en tecnología, educación, entre otras (Martínez, 2008).

Elaboración de infografías: Hacia el desarrollo de las competencias

24. del siglo XXI
Como medio de comunicación, la infografía tiene por función principal transmitir información de manera clara, precisa y coherente, acompañando a la 
información textual escrita o hablada, para explicar o completar determinados aspectos. En este caso, no sustituye al texto informativo hablado o escrito sino que es un recurso visual complementario.

Figura 1.

Definición del concepto de Infografía. Imagen tomada de Morales, 2014.

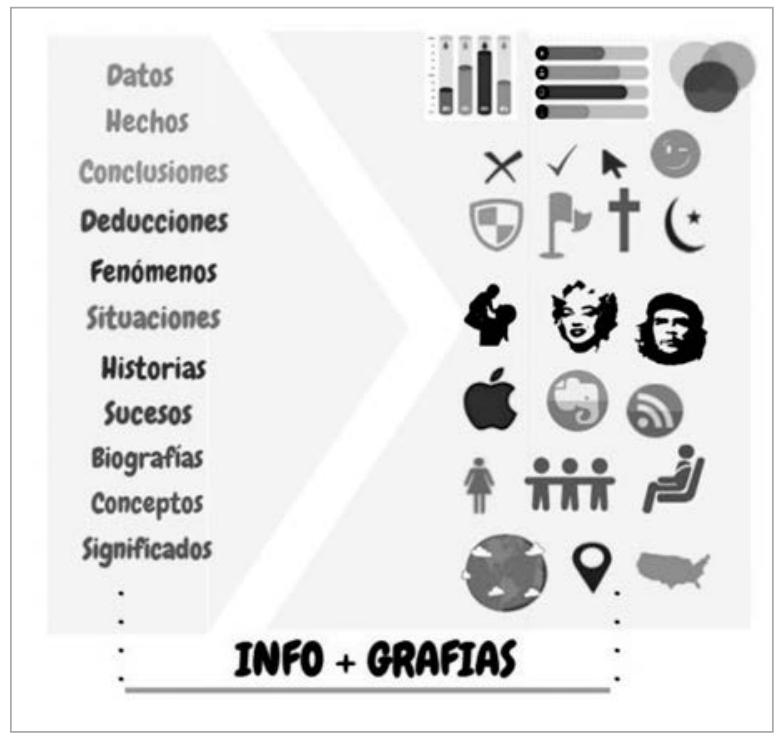

Para llegar a una audiencia determinada, la infografía debe considerar una dimensión estética, la cual es exactamente igual a la de un texto periodístico que debe estar bien escrito y además ser atractivo, agradable de leer (Valero, 2008). En ese sentido, Valero (2010) manifiesta que la infografía digital tiene un fuerte componente estético que permite captar la atención de los usuarios, sin importar que tengan deficiencias en la comunicación visual.

Aun cuando en la creación de una infografía se debe considerar el aspecto estético, este no ha de superponerse a la ética. Teniendo en cuenta que, el concepto de infografía involucra el uso de distintos datos, hechos históricos y científicos es importante que se verifiquen las fuentes de información consultadas, por su naturaleza periodística; ninguna infografía deberá contener información que no sea veraz y comprobable.

El profesor Cairo (2014) expresa que la ética es el esqueleto de la infografía, en otras palabras, la ética es la estructura que sostiene todos los elementos que conforman la infografía, siendo así que lo estético ocupa un segundo lugar, aunque no por ello deja de ser importante puesto que el uso de recursos estéticos ayuda a los lectores acceder de manera interactiva a los elementos que se exponen en la infografía. 


\section{¿Por qué crear y utilizar infografías?}

Es innegable el poder que ha tenido la imagen a través de la historia de la humanidad. Basta con remontarnos a las pinturas rupestres para constatar que desde tiempos pre-históricos, el ser humano organizó un sistema de representación gráfico para explicar las relaciones con su entorno y así, dejar huella del conocimiento adquirido a generaciones posteriores, o basta simplemente revisar las imágenes de cartografía, los bocetos y representaciones de Leonardo Da Vinci, los planos de distintas máquinas, los diagramas de flujo, entre otros registros gráficos para comprender la importancia del uso de imágenes en el desarrollo tecnológico y científico de la sociedad.

Sin embargo, no solo la importancia de la imagen a través de la historia del ser humano da lugar a argumentar la creación y uso de infografías, sino que además, se observa que hoy, más que en cualquier otra etapa de la humanidad, existe una proliferación de imágenes. El surgimiento del cine, la televisión, la Internet y los dispositivos móviles han permitido que los niños y jóvenes estén expuestos a grandes cantidades de información visual (imágenes, gráficos, videos, textos, entre otros.), desarrollando así, con mayor precisión el canal visual.

De hecho, la psiquiatra Xaro Sánchez, especialista en neurociencia de las artes visuales del hospital de Mataró en Cataluña, en una columna periodística de opinión de La Vanguardia afirmaba que "La corteza cerebral de tipo visual es la más extensa, unas cinco veces mayor que la corteza auditiva" (Marín, 2009, p.15). Así mismo, Valero (2010) expresa que: "El conocimiento se adquiere mayoritariamente de los sentidos y muy especialmente de la vista, que ha sido desde siempre la principal puerta de entrada de la cultura y el progreso social; viendo se entiende casi todo" (p.477).

En este sentido, se puede afirmar que las infografías optimizan y agilizan los procesos de comprensión, puesto que se basan en una menor cantidad de texto escrito, precisando mayor información de manera gráfica, esto debido a que la imagen funciona como código universal, lo que exige menos trabajo mental que la lectura.

\section{Infografía y educación}

Se ha expuesto que la infografía no surge en el contexto educativo, sino en el ámbito comunicativo y periodístico, teniendo mayor auge a "partir de la década de los 80 donde las tecnologías tuvieron un fuerte impacto en la prensa gráfica lo cual permitió la incorporación de la informatización y por ende, el empleo de nuevos recursos visuales" (Minervini, 2005, p. 1).

Como consecuencia de "la inminente supremacía de la imagen, los medios gráficos generaron nuevas herramientas con el fin de atraer a un público con

Elaboración de infografías: Hacia el desarrollo de las competencias

26. del siglo XXI renovados hábitos lectores -caracterizado por una lectura veloz y fragmentadaa través de la implementación de infografías" (Minervini, 2005, p. 1). Haciendo su inmersión en distintos ámbitos como en el educativo. 
Hoy en día, gracias a su potencialidad comunicativa e interactiva resulta ser un recurso didáctico útil para ser trasladado al contexto educativo e incorporarse en el proceso de enseñanza-aprendizaje; tomando mayor relevancia cuando se soporta en los recursos tecnológicos actuales y en las herramientas disponibles para ser usadas por cualquier persona que esté interesada en su aplicación como medio de transmisión de mensajes.

El Ministerio de Educación de El Salvador (2013) expone que: "Las infografías pueden ser canteras de información y motores para la expresión oral y escrita en el aprendizaje de lenguas, facilitadoras de la comprensión de los contenidos curriculares (...). Vehículos de expresión y creatividad utilizando tecnologías para su producción" (p.1). En ese mismo sentido, Reinhardt (2010) afirma que las infografías como recursos didácticos pueden brindar beneficios significativos en el proceso de enseñanza-aprendizaje.

De hecho, investigaciones educativas como las presentadas por Minervini (2005) y Valero $(2008,2010)$ han demostrado que las infografías pueden ser adaptadas de acuerdo con tres aspectos generales: en primer lugar, a las necesidades de aprendizaje y necesidades pedagógicas, hace énfasis en la adquisición de conocimiento, teniendo en cuenta las características del usuario, edades, comportamientos sociales, etapa de desarrollo cognitivo, entre otros. En segundo lugar, de acuerdo con la estructuración de los contenidos, donde es primordial el tipo de aprendizaje que se quiere lograr, a partir de ahí, se deberán elaborar infografías para que así, fortalezcan procesos cognitivos. En tercer lugar, de acuerdo con la estructuración de los contenidos, donde es primordial el tipo de aprendizaje que se quiere lograr. A partir de ahí, se deberán elaborar infografías para que así, fortalezcan procesos cognitivos.

Finalmente, el contexto o situación en la que será utilizada, teniendo en cuenta el espacio físico o geográfico en donde se utilizará: un libro, una pantalla, dentro del aula, fuera de ella, para una clase o durante todo el año. En forma individual o colectiva, una infografía se utiliza como disparador de un tema, como idea central, como aplicación de conocimientos, como generalizador de otros temas.

De esta manera, se pueden consultar algunos referentes experienciales del uso de infografías en el ámbito educativo, como por ejemplo: Literatura Infográfica a la Vanguardia presentada por López (2012) y Río Tajo en la ciudad de Madrid, España, presentada por Rodríguez (2008). Estas son experiencias que se caracterizan por aproximar a los estudiantes a la concepción moderna de la información, vista ésta como una necesidad omnipresente en el mundo actual.

\section{Elaboración de infografías y aprendizaje}

Edgar Dale desarrolló en 1964 una infografía conocida con el nombre de "Cono de la experiencia" esta, resulta ser una ayuda visual para "explicar las interrelaciones existentes entre los diversos tipos de materiales audiovisuales, así 
como de sus posiciones individuales en el proceso del aprendizaje" (Dale citado en Castillo, 1999, p. 1).

\section{Figura 2.}

Cono de la experiencia. Desarrollado en 1964 por el pedagogo norteamericano Edgar Dale. Tomada de Martínez, 2008.

\section{CONO DE LA EXPERIENCIA}

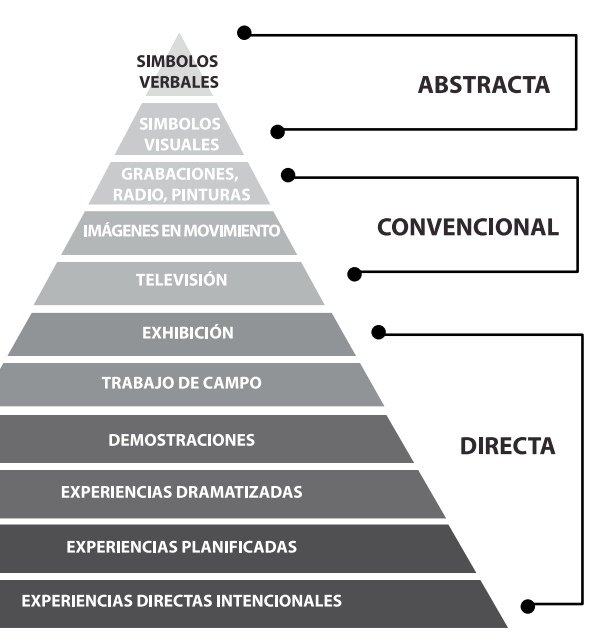

A partir de lo expuesto en los distintos niveles del Cono de la experiencia, se puede analizar la relación directa entre el proceso de creación de una infografía y el aprendizaje.

En el primer nivel se ubican aquellas experiencias con más detalles, cuyo objetivo es el contacto directo con la realidad; el alumno es el responsable del resultado, es decir, su participación es esencial para alcanzar el aprendizaje esperado (Barahona, 2005). Así, al iniciar una infografía el estudiante puede realizar entrevistas, búsqueda de información en fuentes primarias, relatos, testimonios, entre otros, que le permiten estar en contacto directo con el objeto de estudio. En el segundo nivel se agrupa un conjunto de medios que incluye una participación indirecta del alumno, quien no puede modificar ni alterar los acontecimientos y hechos observados, pero su acción no debe limitarse a una observación pasiva, sino que debe incorporarse de forma activa en el proceso de observación (Barahona, 2005). Es así como el estudiante puede visitar distintos sitios de interés como empresas, museos, parques o acceder a recursos audiovisuales. Estos últimos, tienen la ventaja que le permiten al observador tener el control de la reproducción.

Elaboración de infografías: Hacia el desarrollo de las competencias

28. del siglo XXI
En la última zona del Cono de la experiencia se ubican los medios que tienen mensajes compuestos por símbolos e íconos, que representan cosas, hechos o procesos de manera abstracta. El alumno brinda un significado particular a 
cada signo, determinado por su contexto cultural (Barahona, 2005). De igual forma, al realizar una infografía se utilizan distintas representaciones simbólicas como íconos, gráficas, diagramas de flujo, líneas de tiempo, entre otras.

Las infografías al estar compuestas por distintos elementos (texto, imagen, gráficos, vídeos, entre otros) y ser el resultado de una búsqueda específica y válida de información permiten comunicar un mensaje de manera concreta y coherente. Son además una excelente ayuda visual para presentar el proceso de aprendizaje de un individuo. Entonces, por corresponder a un formato de modelo conceptual nos acercarían a la posibilidad de lograr mejores resultados en la construcción del pensamiento y el aprendizaje.

Los alumnos antes de ingresar al sistema educativo han recibido estímulos mediáticos, conocen de lenguaje audiovisual e informático de una manera práctica e intuitiva. Es por ello, que se debe promover una nueva alfabetización, tan fundamental para que la escuela pueda competir con ese bombardeo visual al que están sometidos los estudiantes (Reinhardt, 2010).

De esta forma, la taxonomía propuesta por Boss \& Krauss (2010) sostiene que la generación de infografías apoya el aprendizaje de un individuo. Por un lado, la búsqueda, recopilación e interpretación de la información genera un aprendizaje a profundidad. Por otro, la organización de la información en un formato visual hace que las cosas sean visibles y debatibles. Como resultado de lo anterior, la implementación de infografías puede incrementar los niveles de aprendizaje al utilizarla como lenguaje gráfico, porque los estudiantes interactúan al crearlas, ya sea de manera tangible o de forma digital.

Sin embargo, que los recursos didácticos multimedia sean altamente significativos y efectivos dependerá de elementos como su diseño, utilización y pertinencia en función de los objetivos de aprendizaje planteados (Álvarez y Fernández, 2009; Boza, Toscano y Méndez, 2009; citados por Muñoz, Fuentes y González, 2012). Lo que se busca al integrar las infografías en el aula es lograr un determinado aprendizaje en los estudiantes, que la información recibida sea clara y precisa.

Para Muñoz et al (2012) "La elaboración de materiales didácticos multimedia resulta una tarea ardua y compleja en la que confluyen componentes de carácter técnico, gráfico, disciplinar y pedagógico, entre otros" (p.305). Para lograr cumplir esos componentes se requiere de un alto nivel formativo y unas competencias desarrolladas por parte de los docentes que decidan crear e integrar este tipo de materiales didácticos multimedia en sus clases.

\section{Infografía y competencias del siglo XXI}

Pérez (2000, citado por Reinhardt, 2010) expresa que "La relación entre comunicación y educación, en la sociedad de la información, es un territorio de preocupación general. Constituye, sin duda, uno de los campos decisivos 
de la transformación de la cultura y de la educación en nuestros días, y una de las áreas en las que realmente la humanidad se juega su auténtico progreso, 0 retroceso, en los años venideros (p. 123)

En ese sentido, los profesores serían los primeros comunicadores porque están en contacto directo con el alumnado, son quienes transmiten los mensajes. Enseñar es comunicar, reflexionar sobre las modalidades que le permiten al alumno comprender lo que se le dice y a los docentes tomar en cuenta las reacciones de ellos. Sin embargo, en la actualidad la educación vinculada a la pedagogía y la didáctica ha sido tema de discusión por su falta de modernización y actualización (Reinhardt, 2010).

Esto último, cobra mayor importancia en la actualidad debido a que existe una tendencia al crecimiento exponencial de la información y el conocimiento. Según la UNESCO (2010), la información mundial que se produce cada año es casi duplicada a la del año anterior. Para darse una idea de lo que esto significa, se puede recordar la antigua leyenda persa sobre un cortesano que ofrendó a su rey un bello tablero de ajedrez.

\section{Figura 3.}

Crecimiento exponencial de la información, ejemplo tomado de UNESCO, 2010.

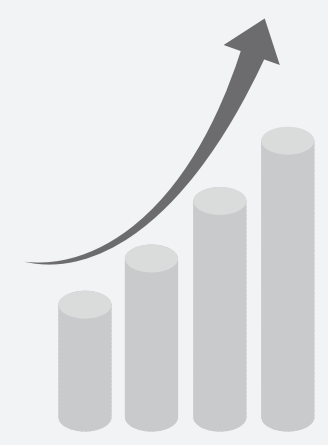

El rey le preguntó qué regalo podía dar el cortesano a cambio. Al principio, el cortesano modestamente objetó. Viendo la insistencia, él respondió que estaría feliz con un grano de arroz para la primera casilla del tablero, dos granos por la segunda casilla, cuatro granos para el tercero, y así sucesivamente para cada casilla del tablero. El rey estuvo de acuerdo. Por la décima casilla el rey había dado al cortesano 1024 granos de arroz, una simple taza, y seguía sonriendo. Pero por la plaza 32a justo la mitad de la tabla, los siervos del rey estaban buscando 4.294.967.296 granos, casi tanto como un cultivo de arroz de un campo grande. El rey comenzó a parecer preocupado. En poco tiempo el reino se había quedado sin arroz.

(Traducción realizada por los autores. Texto original: UNESCO, 2010)

Es así que, "los expertos estiman que 24 millones de nuevas entradas del blog se actualizan diariamente y cada día más de mil millones de canciones son compartidas a través de Internet" UNESCO (2010, p. 10). El conocimiento no es lo mismo que información, pero, al igual que la información, el conocimiento se está expandiendo de manera exponencial.

Elaboración de infografías: Hacia el desarrollo de las competencias

30. del siglo XXI
Según una estimación realizada por Resta y Patru (citados por UNESCO, 2010), cerca de 7.000 artículos científicos, técnicos y de medicina se publican diariamente. La educación debe estar preparada para recibir la información 
que surge constantemente y que se relaciona directamente con los procesos de enseñanza-aprendizaje.

Información y conocimiento son indudablemente el resultado del auge que en los últimos años han tenido las Tecnologías de la Información y la Comunicación, incorporándose en todos los aspectos de la vida actual, teniendo una implicación directa en la manera cómo nos comunicamos. Es evidente, que hoy en día, existe mayor predominancia de información que comunicación; por ello, se expone que el mundo se encuentra en la sociedad de la información.

En esa misma lógica, el principal propósito del sistema educativo será desarrollar en los educandos habilidades y competencias que les permita desempeñarse de manera eficiente, durante y después del ciclo formal de educación en el inmenso mar de información y conocimiento que se amplía con el pasar de los días. En otras palabras, ante la gran cantidad de información que se encuentra en la actualidad, es indispensable que el profesor de aula, incorpore herramientas tecnológicas que faciliten a sus estudiantes los procesos de comprensión encaminados al desarrollo de competencias propias de esta sociedad.

En esa medida, la OCDE (2010) expresa que el desarrollo social, económico, cultural, y político exige que los sistemas educativos brinden nuevas formas de aprender y hacer las cosas, y nuevas habilidades y competencias. Estas habilidades y competencias se denominan normalmente: "Habilidades y competencias del siglo XXI con el fin de indicar que están más relacionadas con las necesidades de los modelos emergentes de desarrollo económico y social que con aquellas del siglo pasado al servicio del modo industrial de producción" (p.3). Entre ellas las competencia digital, informacional, multimodal y comunicativa, todas ellas enmarcadas dentro del desarrollo integral del ser humano.

En el ámbito educativo, Reinhardt (2010) expresa: "No tenemos por qué limitarnos a una educación meramente lógico-racional negando que existen otras capacidades mentales que son necesarios desarrollar, como ser el sentido artístico, emotivo, creativo, perceptivo y relacional; que permiten un desarrollo integral del ser"(p.126).

Con todo ello, es importante que los docentes y formadores de estudiantes del siglo XXI, sean conscientes de la relevancia e influencia no solo de los recursos digitales que se pueden encontrar en la web y el crecimiento exponencial de la información; sino también de la verificación de fuentes y veracidad de información. Así como del papel predominante de la imagen y de la competencia visual, como representaciones de la apariencia visual de un objeto, para comunicar un mensaje (Maris \& Noriega, 2010). 
En esa misma línea, si las habilidades y competencias propias del siglo XXI están directamente relacionadas con la gestión del conocimiento (búsqueda, selección y organización de información, como se mencionó anteriormente), se vuelve una tarea del docente revisar y plantear diversos proyectos que promuevan los aspectos que ello implica.

Proyectos que se pueden abordar desde la elaboración y uso de la infografía, tomando en cuenta que la infografía, en el proceso de enseñanza aprendizaje, es un recurso didáctico que desde su uso propicia el entendimiento de conceptos, como lo expresa Valero (2012). Las infografías aumentan y clarifican considerablemente el nivel de conocimiento de los alumnos acerca de temas estudiados.

Así, de manera general se visualiza, al elaborar una infografía, una relación entre habilidades, competencias, gestión del conocimiento y ética, puesto que todas ellas, involucran procesos de búsqueda, selección, evaluación, organización, re-estructuración de información, así como, el uso de recursos digitales para generar nuevas ideas, que pueden ser comunicadas e intercambiadas, dando prioridad a las fuentes de información y con ello a la veracidad de los hechos, citas y demás elementos consultados.

Con todo lo anterior, se evidencia que las infografías tienen un potencial pedagógico que permiten el desarrollo de competencias propias de la sociedad contemporánea como lo son: la competencia comunicativa, la informática y la digital. El desarrollo de la competencia comunicativa se logra evidenciar cuando el estudiante al crear su infografía, organiza los elementos a utilizar (texto, imagen, audio, vídeo, entre otros), lee sobre el contenido que incorpora, hace una síntesis del mismo, expone de manera clara y precisa en qué consiste el tema desarrollado en la infografía.

En ese sentido, Colombia Aprende (2013) expone que: "A medida que se adquieren herramientas y experiencias, para el respectivo despliegue de las competencias comunicativas, el ejercicio auténtico de la producción discursiva y la interacción comunicativa, se dará de manera clara, oportuna y precisa, entre las sociedades que favorezcan su desarrollo" (p.1).

De igual forma, la competencia en informática se desarrolla, en la medida que el estudiante, se enfrenta a plantear estrategias para la búsqueda de información pertinente, así como a la selección, la organización, verificación de fuentes de información, edición y presentación de manera clara, objetiva y coherente en el producto final: la infografía.

Elaboración de infografías: Hacia el desarrollo de las competencias

32. del siglo XXI
Además, la infografía al estar organizada como un elemento de comunicación multimodal, da un valor agregado para transmitir o representar procesos y hechos, presentando de esta manera información con detalles que seguramente son 
difíciles de indicar a través del lenguaje escrito u oral únicamente. Con esto se permite evidenciar una serie de atributos que las hace más llamativas e impactantes para quienes reciben el mensaje. Entre estos podemos mencionar: alta funcionalidad, entendida como la transmisión de un contenido eficaz y eficiente; dinamismo, como resultado de la interacción de los distintos recursos multimedia utilizados; novedad, enfatizando un contenido relevante y poco estudiado; todos relacionados con el desarrollo de competencia multimodal.

Finalmente, se logra evidenciar la competencia digital cuando el estudiante maneja los sistemas relacionados con aplicaciones digitales, y los utiliza para presentar un producto que cumple con las características propias de una infografía.

\section{Aproximación: ¿Cómo incorporar infografías en el aula?}

A continuación, se describe el proceso que el docente debe llevar a cabo para incorporar infografías en el aula; para ello, se desarrolló un ejercicio con tres grupos de estudiantes de grado noveno del Colegio María Mercedez Carranza, Bogotá, D. C.

El profesor, coautor de este artículo, quien imparte la asignatura Informática, les asignó a sus estudiantes el tema "Arte Digital". La finalidad de la actividad era crear una infografía, teniendo en cuenta, previamente, una serie de elementos expuestos por el docente:

- Qué es una infografía

- Características de la infografía

- Elementos de la infografía

- Ejemplos de infografías

- Aplicación de las infografías

A partir del tema asignado, el docente orientó la actividad en una serie de pasos, que les permitió a los estudiantes comprender mejor el proceso de cómo elaborar una infografía.

Figura 4.

Definición del concepto de Infografía y pasos para su diseño (Morales, 2014). 


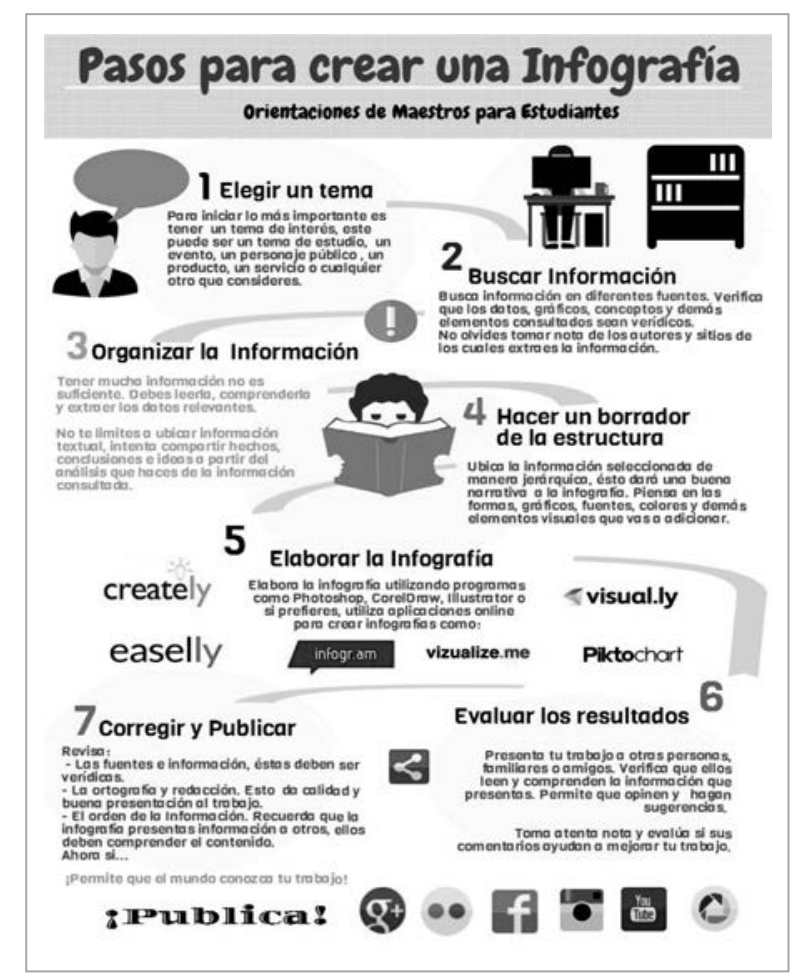

Figura 5 y 6.

Dos ejemplos como resultado de dicha actividad:
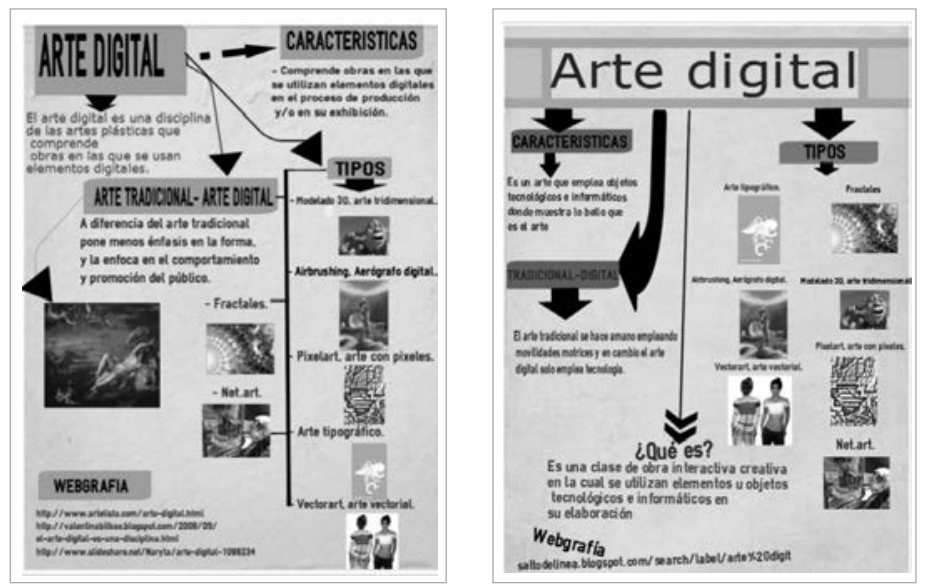

Elaboración de infografías: Hacia el desarrollo de las competencias

34. del siglo XXI

\section{Conclusión}

Minervini (2005) expresa que: "Las infografías producen nuevos parámetros de producción que permite optimizar y agilizar los procesos de comprensión (...). Ante el surgimiento de esta técnica y su potencialidad comunicativa, nace el interés por vincular los gráficos informativos a la práctica educativa (p.2). Siguiendo con lo expuesto por Minervini (2005), las infografías al presentarse 
como una combinación de elementos visuales, aporta un despliegue de información clara, precisa y coherente que sirve para explicar o complementar aspectos complejos, los cuales, son difíciles de exponer de manera textual o hablada. Esto se produce porque los seres humanos a través de la historia, han desarrollado más el canal visual que el auditivo.

Gracias al potencial comunicativo e interactivo de la infografía, esta resulta ser un recurso didáctico útil para ser utilizado en el proceso de enseñanza-aprendizaje, facilita la comprensión de los contenidos curriculares, estimula el repaso o la ampliación de temas trabajados dentro del aula, motiva el conocimiento, la expresión y creatividad a partir del uso de las nuevas tecnologías para su elaboración y producción.

Lo expuesto anteriormente, deja en evidencia que las infografías son un potente recurso tecnológico; el docente debe apropiarse de esta tecnología emergente y comprender su uso pedagógico, para ello, debe estar consciente de que la infografía didáctica, se puede entender desde tres categorías expuestas por Reinhardt (2010): "Necesidades o características del usuario. Estructuración de los contenidos y contexto o situación en la que será utilizada (p.133).

Elaborar infografías permite tener experiencias concretas, convencionales y abstractas, tal como lo expone Edgar Dale en el Cono de la Experiencia. Por tanto, esto implica búsqueda, selección, organización, edición e interpretación tanto de información, como de representaciones simbólicas. En este sentido, se reconoce que la elaboración de infografías tiene una repercusión directa en el Aprendizaje Significativo de un individuo. En el crecimiento exponencial de la información y el conocimiento que se encuentran en la sociedad actual, las infografías facilitan el uso de recursos audiovisuales, que al ser incorporados en las aulas de manera coherente y con un propósito definido ayudan a promover la alfabetización multimodal, tan esencial para que la escuela pueda competir con el bombardeo de estímulos mediáticos que reciben todos días los alumnos (Reinhardt, 2010).

Con respecto al desarrollo de competencias siglo XXI, se evidencia que las infografías permiten el desarrollo de la competencia comunicativa (hablar, escuchar leer y escribir), la competencia informática (buscar, seleccionar y organizar información), la competencia multimodal a partir del uso de distintos modos de representación y la competencia digital (uso de programas digitales). Ferrés (1989, citado por Minervini, 2005) plantea que: "Si la escuela quiere edificar un puente con la sociedad, tendrá que asumir plenamente el audiovisual como forma de expresión diferenciada. Es decir, además de educar en la imagen, tendrá que educar a través de la imagen" (p.2).

En definitiva, los docentes deben tomar consciencia de la importancia de desarrollar competencias orientadas al siglo XXI, buscar aquellos recursos 
tecnológicos que contribuyen al desarrollo de las mismas, se hace hincapié que no deben dejarse llevar por "moda" o por el surgimiento de herramientas en momentos determinados. Las infografías, como recurso didáctico, son una forma adecuada para desarrollar competencias en los estudiantes.

\section{Referencias}

Barahona, S. (2005). Aprendizaje Significativo y Uso de Medios Audiovisuales. [En línea]. Disponible en http://www.utpjminfante.netne.net/aarchivosutp/ tics/Barahona\%20Aprendizaje\%20y\%20uso\%20de\%20medios\%20 audiovisuales.pdf Recuperado 14/03/2014.

Boss, S., \& Krauss, J. (2010). Aprendizaje por proyectos con herramientas digitales, internet y web 2.0. Eduteka. [En línea]. Disponible en: http://www.eduteka. org/Aprendizajem HerramientasDigitales. php recuperado el: 12/03/2014

Cairo, A. (2014). La ética prima sobre la estética en la infografía periodística. Red Ética Segura. [En línea]. Disponible en http://eticasegura.fnpi. org/2014/01/14/la-etica-prima-sobre-la-estetica-en-el-periodismoinfografico-alberto-cairo/ recuperado: 03/03/2014.

Castillo, J. (1999). La Telaraña de experiencias. Universidad Nacional del Centro de Perú. [En línea]. Disponible en http://www.sev.gob.mx/actualizacion/ files/2014/02/EducacionAmbientalPracticaDocente_III/TEMA4_ SESION_7-8/CONO_EXPRIENCIAS_DALE.pdf Recuperado: 20/03/2014.

Colombia Aprende. (2013). ¿Qué son las Competencias Comunicativas? [En línea]. Disponible en http://www.colombiaaprende.edu.co/html/ competencias/1746/w3-article-243909.html recuperado: 20/03/2014.

López, J. (2012). Literatura infográfica a la vanguardia. Eduteka. [En línea]. Disponible en: http://www.eduteka.org/proyectos. php/2/9291 recuperado: $17 / 03 / 2014$.

Marín, B. (2009). La infografía digital, una nueva forma de comunicación. (Tesis doctoral). Universidad Autónoma de Barcelona. España. [En línea]. Disponible en:http://www.tdx.cat/bitstream/handle/10803/48653/bemol del.pdf;js essionid =9DC898082728B55C9C 17CF982BE76273.tdx1? sequence $=1$ recuperado: 08/03/2014.

Maris, S., \& Noruega, M. (2010). La Competencia Espacial. Evaluación de alumnos de nuevo ingreso a la Universidad. Educación Matemática, 22(2), 65-91. [En línea]. Disponible en: http://www.scielo. org.mx/pdf/ed/ v22n2/v22n2a4.pdf recuperado: 08/03/2014.

Martínez, A. (2008). Cono de la Experiencia. [Fotografía]. Disponible en: http:// ecoforman. blogspot.com /2008_05_13_archive.html recuperado: $18 / 03 / 2014$.

Minervini, M. (2005). La infografía como recurso didáctico. Revista Latina de Comunicación Social 59 ,enhttp://www.ull.es/publicaciones/ latina/200506minervini.pdf recuperado: 17/03/2014.

Elaboración de infografías: Hacia el desarrollo de las competencias

36. del siglo XXI 
Morales, H. (2014). Definición del concepto de Infografía. [Imagen].Elaboración para el presente artículo.

Morales, H. (2014). Orientaciones para crear infografía. [Imagen]. Elaboración para el presente artículo.

Muñoz, P., Fuentes, E., \& González, M. (2012). Necesidades formativas del profesorado universitario en infografía y multimedia. Revista de Investigación Educativa 30(2), 303-321. [En línea]. Disponible en http:// revistas.um.es/rie/article/view/rie.30.2.118971/148861 recuperado el: $14 / 03 / 2014$.

OCDE. (2010). Habilidades y competencias del siglo XXI para los aprendices del nuevo milenio en los países de la OCDE. [En línea]. Disponible en http:// recursostic.Educacion.es/ blogs/ europa/media/blogs/europa/informes/ Habilidades_y_competencias_siglo21_OCDE.pdf Recuperado: 15/03/2014.

Reinhardt, N. (2010). Infografía Didáctica: producción interdisciplinaria de infografías didácticas para la diversidad cultural. Centros de Estudios en Diseño y Comunicaciones. 119-191. [En línea]. Disponible en: http://www. scielo.org.ar/pdf/ccedce/n31/n31a03.pdf Recuperado: 18/03/2014.

Rodríguez, R. (2008). Práctica de wq: el río tajo en Madrid. Eduteka. [En línea]. Disponible en: http://www.eduteka.org/proyectos.php/1/120 recuperado: 10/06/2014.

UNESCO (2010). Exponential growth in information and knowledge. [Fotografía]. Disponible en http://unesdoc.unesco.org/images/0018/001892/189216e. pdf recuperado: 20/03/2014.

UNESCO (2010). ICT Transforming Education. A Regional Guide". [En línea]. Disponibleen http://unesdoc.unesco.org/images/0018/001892/189216e. pdf recuperado: $11 / 03 / 2014$.

Valero, J. (2010). La comunicación de contenidos en la infografía digital. Estudios sobre el mensaje periodístico, 16, 469-483. [En línea]. Disponible en http:// revistas.ucm.es/index.php/ ESMP/article/view/ESMP1010110469A/1 1514 recuperado: 17/03/2014.

Valero, J. (2008). La infografía digital en el ciberperiodismo. Revista Latina de Comunicación Social 63, 492-504. La Laguna (Tenerife): Universidad de La Laguna. [En línea]. Disponible en: http://www.revistalatinacs. org/08/42_799_65_Bellaterra/latina_art799.pdf recuperado: 05/04/2014. 